\title{
thebmj
}

Letters Papers with industry ties

\section{Classic confounding conflicts}

BMJ 2009; 338 doi: http://dx.doi.org/10.1136/bmj.b2397 (Published 15 June 2009) Cite this as: BMJ 2009;338:b2397

\section{Stephen J Evans, professor of pharmacoepidemiology 1}

${ }^{1}$ London School of Hygiene and Tropical Medicine, London WC1E 7HT

stephen.evans@Ishtm.ac.uk

The paper by Jagsi et al in Cancer examining conflicts of interest in published clinical cancer research and reported by Tanne may be an example of classic confounding.12The industry funded trials may differ from non-industry funded trials in a way-for example, the treatments used-that is associated with the outcome. The treatments they compare are actually more effective.

The authors themselves note this, though not very clearly. Industry funded trials may not distort results at all (which is not the impression left in the reader's mind after reading the BMJ), but they address different questions.

They may choose to investigate areas of cancer where success is likely to be greater. The questions they address and the designs of the studies may be different. This is bias, but of a very different nature to the idea that they distort results. The evidence is they tend to interpret similar results with a more positive spin, but the results themselves are not distorted.

Had Jagsi et al compared like with like in terms of the types of trials they may (or may not) have found similar results. The paper in Cancer has not answered the correct question.

\section{Notes}

Cite this as: BMJ 2009;338:b2397

\section{Footnotes}

- Competing interests: None declared.

\section{References}

1. Jagsi R, Sheets N, Jankovic A, Motomura AR, Amarnath S, Ubel PA. Frequency, nature, effects, and correlates of conflicts of interest in published clinical cancer research. Cancer2009 May 11, doi: $10.1002 /$ cncr. 24315

2. Tanne JH. Cancer research papers with industry ties more likely to report favourable results. 
BMJ2009;338:b2052. (20 May.) 